\title{
TEM Study of Amorphous Carbon Nanotubes Produced by Direct Chlorination of Ferrocene
}

\author{
E. Urones-Garrote, ${ }^{*}$ D. Ávila-Brande, ${ }^{*}$ N.A. Katcho, ${ }^{*}$ A. Gómez-Herrero, ${ }^{* *}$ A.R. Landa-Cánovas, \\ $* * *$, L.C. Otero-Díaz, ${ }^{*} * *$ \\ * Departamento de Química Inorgánica, Fac. CC. Químicas, Universidad Complutense, E-28040, \\ Madrid, Spain \\ ** Centro de Microscopía Electrónica, Universidad Complutense, E-28040, Madrid, Spain \\ *** Inst. Ciencia de Materiales de Madrid, CSIC, E-28049, Madrid, Spain
}

Nanocarbons are attracting considerable attention in the last years in the field of fundamental and applied research $[1,2]$, due to their promising applications. They can be defined as carbon materials whose size and/or structure is controlled at the nanometer scale: nanosized and nanostructured carbon.

The chlorination of metal carbides is a well-known method to produce nanostructured carbon, according to the reaction: $\mathrm{MC}_{\mathrm{x}}(\mathrm{S})+\mathrm{yCl}_{2}(\mathrm{~g}) \rightarrow \mathrm{xC}(\mathrm{s})+\mathrm{MCl}_{\mathrm{y}}(\mathrm{g})$. The metal atoms are eliminated by the production of volatile metal halides. However, the direct chlorination of metallocenes has not been fully explored in order to produce nanostructured carbon. We have reported preliminary results about the preparation of several carbon nanostructures by chlorination of ferrocene $-\mathrm{Fe}\left(\mathrm{C}_{5} \mathrm{H}_{5}\right)_{2}$ under different temperature conditions $\left(200-900^{\circ} \mathrm{C}\right)$ [3]. In this work, we are presenting the detailed characterization of amorphous carbon nanotubes from several samples prepared by direct chlorination of ferrocene $\left(\mathrm{T}=100,150,200^{\circ} \mathrm{C}\right)$, via TEM and associated techniques (EELS, XEDS, HRTEM) and SEM.

We have observed the presence of amorphous carbon nanotubes, with different dimensions according to the reaction temperature. Figure 1 includes SEM micrographs of carbon nanotubes observed at $100{ }^{\circ} \mathrm{C}$ (Fig. 1a) and $150^{\circ} \mathrm{C}$ (Fig. 1b). Apparently, the walls thickness increases with the reaction temperature, whereas the external diameter of the tube is always around $500 \mathrm{~nm}$ in these samples. XEDS analyses reveal remains of $\mathrm{Cl}$ and $\mathrm{Fe}(<10 \%)$ in both samples. In the sample prepared at $200{ }^{\circ} \mathrm{C}$, carbon nanotubes with a length of several micrometers have been observed (see the SEM micrograph of Figure $2 a)$ together with other nanostructures. The TEM image of Figure $2 b$ shows the typical amorphous open-ended CNTs observed in this sample. Their external diameter is $\sim 70 \mathrm{~nm}$ and the inner one is $\sim 10 \mathrm{~nm}$, presenting thick walls of $30 \mathrm{~nm}$. The inner walls are always straight in contrast with the wavy nature of the outer walls. An enlargement is shown in the inset. In order to evaluate the evolution of the CNTs prepared at $200^{\circ} \mathrm{C}$, a portion of this sample was annealed at $900^{\circ} \mathrm{C}$ during 60 minutes. Apparently, the outer diameter of the CNTs seems to be smaller after the annealing proccess, whereas the inner one is larger. Thus, the nanotubes shown in Figure 3, present an outer diameter of $\sim 45 \mathrm{~nm}$ and an inner one between 13 and $15 \mathrm{~nm}$. A HighResolution TEM image of the wall of the nanotube is shown in Figure $3 b$. The differences in the ELNES spectra of the different samples (Figure 3c) are due to the nature and degree of disorder of the graphene layers.

[1] O.A. Shenderova et al., Crit. Rev.Solid State Mater. Sci. 27 (3/4) (2002) 227.

[2] M. Inagaki et al., Carbon 42 (2004) 1401.

[3] E.Urones-Garrote et al., Carbon 43 (2005) 978.

[4] We thank the financial support from the project PR27/05-13982 (Santander-Complutense). 

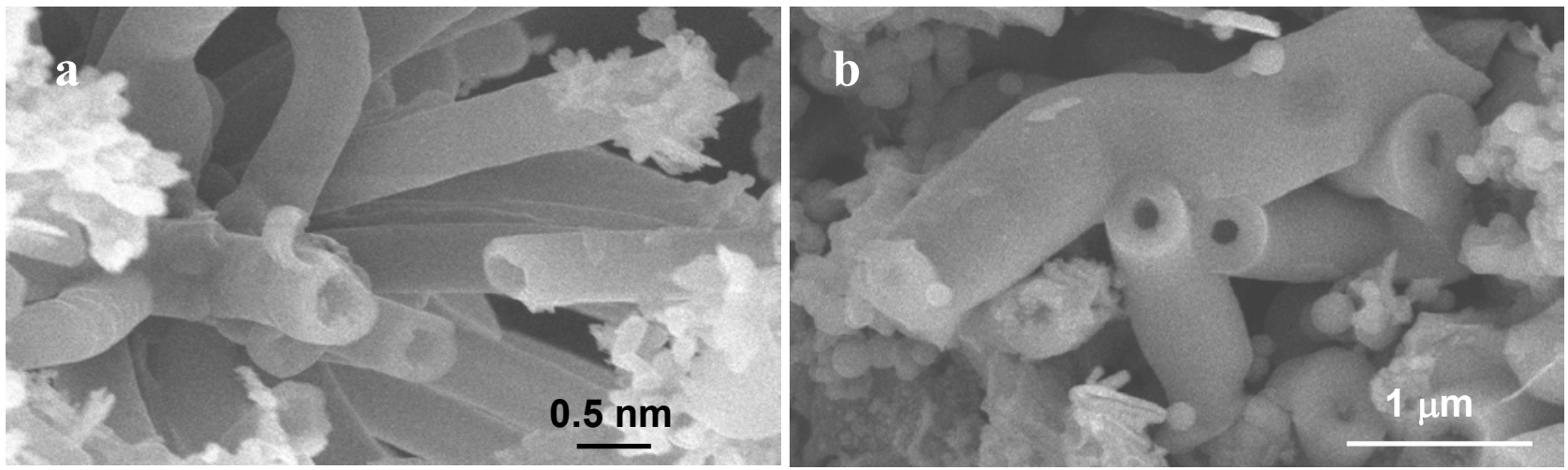

Fig. 1. Carbon nanotubes observed in the sample prepared at $100{ }^{\circ} \mathrm{C}$ (a) and at $150{ }^{\circ} \mathrm{C}(\mathrm{b})$
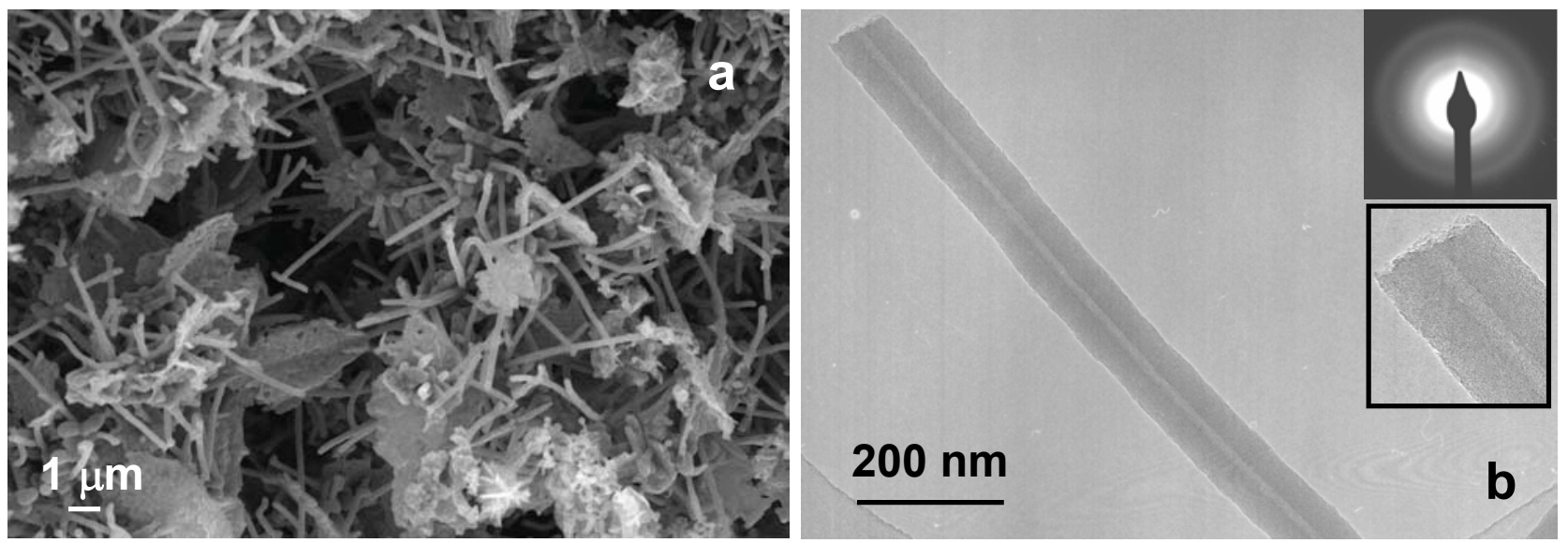

Fig. 2. (a) SEM micrograph of the nanotubes observed in the sample prepared at $200^{\circ} \mathrm{C}$. (b) TEM image of a typical amorphous carbon nanotube. The FFT and an enlargement of the nanotube end are included as insets.
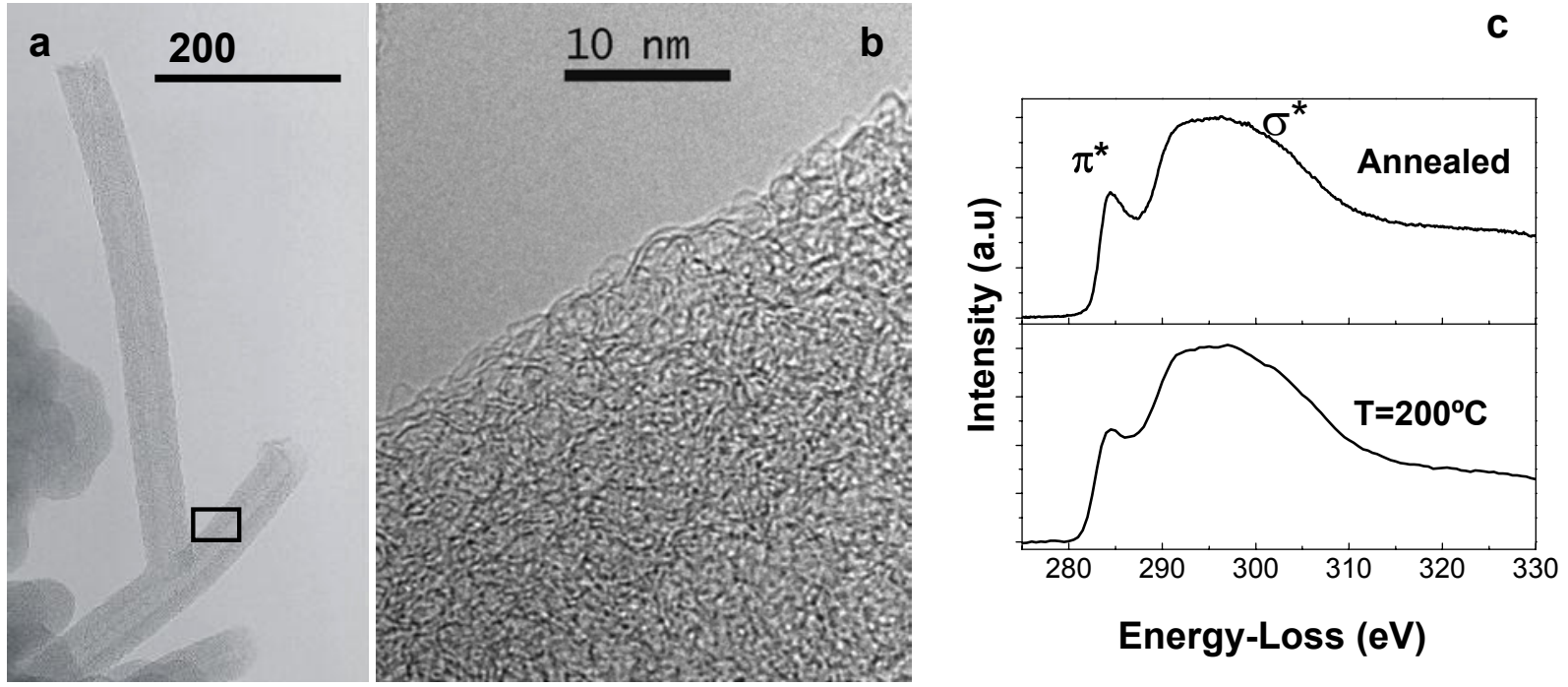

Fig 3. (a) Amorphous carbon nanotubes of the sample annealed at $900^{\circ} \mathrm{C}$. (b) High resolution image of the nanotube wall squared in (a). (c) ELNES spectra of a nanotube prepared at $200{ }^{\circ} \mathrm{C}$ and from a nanotube of the sample annealed at $900^{\circ} \mathrm{C}$. 